\title{
Spigelian hernia-cryptorchidism syndrome
}

INSERM

\section{Source}

INSERM. (1999). Orphanet: an online rare disease and orphan drug data base. Spigelian hernia-cryptorchidism syndrome. ORPHA:314432

Spigelian hernia-cryptorchidism syndrome is a rare developmental defect during embryogenesis characterized by a ventral, uni- or bilateral protrusion of extraperitoneal fat, peritoneum and/or intra-abdominal organs through a defect in the spigelian fascia (Spigelian hernia), associated with ipsi- or bilateral undescended testis (usually found within or just beneath the hernial sac) in male neonates. The gubernaculum and/or inguinal canal may be absent. 